\title{
PENGARUH KETERAMPILAN EASEL TERHADAP KEMAMPUAN VOKASIONAL SISIWA TUNARUNG KELAS IV SDLB-B DI SLB-B DAN AUTIS TPA JEMBER
}

\author{
Riyan Hariyanto \\ PLB IKIP PGRI Jember \\ Email: Riyanhariyanto64@gmail.com
}

\begin{abstract}
Abstrak
Penelitian ini menggunakan metode pre eksperimen dengan desain penelitian "One Group pre test dan post test desain”. Subjek penelitian ini adalah siswa tunarungu kelas IV SDLB-B yang jumlah 4 orang. Penelitian ini dilakukan sebanyak 6 kali pertemuan yang dilakukan pada pre test 1 kali, 4 kali treatment dan terakhir dilakukan post test sebanyak 1 kali. Hasil penelitian ini menunjukkan adanya pengaruh keterampilan easel terhadap kemampuan vokasional dengan hasil analisis data yang diperoleh diketahui $\mathrm{n}=4$, dengan, $\alpha=5 \%(0,05)$, yang Kemudian diuji dengan menggunakan rumus uji tanda (sign test). Selanjutnya hasil diperoleh pada pengujian satu sisi di temukan $Z$ hitung $\left(Z_{H}\right)=2$ dan dibandingkan dengan nilai kritis satu sisi 1,645 , sehingga $Z_{H} \geq Z_{\text {tabel }}$ yaitu $2 \geq 1,645$, dan dapat dikatakan bahwa Ho (hipotesis nol) ditolak dan Ha (hipotesis kerja) diterima yang artinya ada pengaruh yang signifikan keterampilan easel terhadap kemampuan vokasional siswa tunarungu kelas IV SDLB-B di SLB-B dan Autis TPA Jember tahun ajaran 2019/2020.
\end{abstract}

Kata kunci : Keterampilan easel, kemampuan vokasional, tunarungu

\section{PENDAHULUAN}

Tunarungu adalah suatu kondisi anak atau orang dewasa tidak dapat memfungsikan pendengarannya. Melinda (dalam Sulfanita, 2018, hlm. 304).

\section{Tunarungu mempunyai} beberapa hambatan diantaranya dalam hal kepribadian, bahasa, hubungan kemasyarakat, maupun dalam kecakapan vokasional. Kecakapan vokasional penting diajarkan kepada siswa tunarungu kemampuan vokasional yang dilakukan melalui keterampilan easel di sekolah luar biasa (SLB). Hal ini dapat mengatasi kebutuhan pada siswa tunarungu yang tidak terpaku pada bidang akademik saja. Ketika siswa tunarungu membunyai kemampuan pada bidang vokasional diharapkan nantinya dapat mempunyai sumber penghasilan sendiri untuk mencukupi kebutuhan hidupnya.

Menurut Ishartiwi (2017) melalui belajar keterampilan dapat meningkatkan Kecakapan hidup. Clark (1979) program yang harus dilakukan dalam pengembangan kemampuan vokasional yaitu (a), bimbingan atau latihan agar kebiasaan-kebiasaan seperti sikap dan nilai-nilai kerja dalam kehidupan sehari-hari, (b) memberikan latihan berupa orientasi berorientasi pada dunia kerja yang realistik (c) memberikan latihan kerja secara nyata agar dalam kehidupan sehari-hari dapat dilaksakan dengan baik.

Berdasarkan kondisi di lapangan terdapat 4 siswa tunarungu yang memerlukan pengembangan dalam kemampuan vokasional di SLB-B dan Autis TPA Jember, 
juga kemampuan vokasional ini diharapkan bermaafaat untuk kehidupan yang akan datang. Hal ini juga didukung oleh pihak sekolah yang mengingikan siswanya memiliki keterampilan vokasional, selain 4 siswa tersebut belum mampu membuat keterampilan easel yang dimana sekolah menginginkan agar agar siswanya dapat mengembangkan keterampilannya.

Kemampuan vokasional ini yang diharapkan bermanfaat untuk kehidupan dimasa yang akan datang. Untuk mengembangkan kemampuan vokasional maka penelitian mengajarkan keterampilan easel. Keterampilan easel merupakan alat penyangga berkaki tiga yang berfungsi sebagai penyangga berkaki tiga untuk mendudukkan kanvas saat melukis atau memajang karya dalam pameran, (Hambor, 2008).

\section{METODE}

\begin{tabular}{ccc}
\multicolumn{2}{c}{ Sebelum memulai kegiatan } \\
peneliti
\end{tabular} rancangan kegiatan terlebih dahulu. Menurut (Arikunto, 2006:44) desain penelitian adalah rancangan yang di buat oleh penelitl untuk kegiatan yang akan dilaksanakan Penelitian ini merupakan penclitian, pre eksperimen dengan desain “ One Group Pretest Posttest Design, Kegiatan dalam penelitian ini agar mengetahui pengaruh keterampilan easel terhadap kemampuan vokasional untuk siswa tunarungu kelas IV SDLBB di SLB-B dan Autis TPA Jember tahun ajaran 2019/2020. Dapat dilihat pada sebagai berikut :

Tabel 1. Desain Penelitian, One

Groups Pretest-Posttest

\begin{tabular}{|l|l|l|}
\hline $\mathbf{O}_{\mathbf{1}}$ & $\mathbf{X}$ & $\mathbf{O}_{\mathbf{2}}$ \\
\hline
\end{tabular}

(Sugiyono, 2017:74)

Keterangan :

$\mathrm{O} 1$ = nilai (pretest) (sebelum

diberi perlakuan)

$\mathrm{X}=$ Treatment atau perlakukan yang diberikan kepada siswa pada waktu proses pembelajaran

$\mathrm{O} 2$ = nilai (posttest) (setelah diberi perlakuan)

Pengaruh penerapan

terhadap kerja memahami

vokasional $=(02-01)$

(Sugiyono, 2017, hlm.74 -

75)

Dalam desain diberi tes awal (pre tes) Kemudian hasil tes awal tersebut akan dijadikan perbandingaan untuk hasil tes akhir yaitu (post test).

Populasi adalah semua individu dalam suatu wilayah tertentu dengan ciri-ciri kebutuhan yang sama. Hal ini sesuai dengan pernyataan. Menurut (Sugiyono, 2017:80). Populasi adalah suatu wilayah yang terdiri atas: obyek dengan kualitas dan karakteristik tertentu. Yang digunakan Sampel pada penelitian adalah siswa tunarungu sedang kelas IV yang berjumlah 4 siswa. 
Tabel 2. Daftar Nama

siswa tunarungu kelas IV di SDLB-

B \& Autis TPA Jember

\begin{tabular}{|c|c|c|c|}
\hline No & Nama & Kelas & $\begin{array}{c}\text { Jenis } \\
\text { kelamin }\end{array}$ \\
\hline 1 & Farhan & IV & Laki-laki \\
\hline 2 & Rian & IV & Laki-laki \\
\hline 3 & Ralfi & IV & Laki-laki \\
\hline 4 & Dani & IV & Laki-laki \\
\hline
\end{tabular}

Pada penelitian ini dua varabel yang terlibat dalam penelitian ini, Variabel Bebas dan variabel terikat.

\section{HASIL DAN PEMBAHASAAN}

Penelitian pre test yaitu sebelum kemampuan siswa tunarungu diberikan intervensi. Hasil belajar siswa dapat dilihat sebagai berikut:

Tabel 3.

Data hasil pre test untuk Nilai kemampuan vokasional siswa tunarungu

\begin{tabular}{|c|c|c|c|}
\hline No & $\begin{array}{c}\text { Nama } \\
\text { siswa }\end{array}$ & $\begin{array}{c}\text { Jenis } \\
\text { kelamin }\end{array}$ & $\begin{array}{c}\text { Nilai pre test } \\
\text { kemampuan } \\
\text { hasil belajar } \\
\text { siswa }\end{array}$ \\
\hline 1 & $\mathrm{~F}$ & $\begin{array}{c}\text { Laki- } \\
\text { laki }\end{array}$ & 50 \\
\hline 2 & $\mathrm{Ri}$ & $\begin{array}{c}\text { Laki- } \\
\text { laki }\end{array}$ & 50 \\
\hline 3 & $\mathrm{Ra}$ & $\begin{array}{c}\text { Laki- } \\
\text { laki }\end{array}$ & 30 \\
\hline 4 & $\mathrm{D}$ & $\begin{array}{c}\text { Laki- } \\
\text { laki }\end{array}$ & 30 \\
\hline & \multicolumn{2}{|c|}{ Rata-rata } & $\mathbf{4 0}$ \\
\hline
\end{tabular}

\section{a. Perlakuan/Treatment}

Dalam Pelaksanaan treatment dibutuhkan 4 kali pertemuan dan alokasi waktu 45 menit, langkahlangkah pelaksanaan perlakukan/treatment:

(1) Langkah pertama siswa tunarungu menyiapkan alat dan bahan untuk membuat easel misalnya

a) Alat : gergaji, bor, obeng, baut/mur, pensil, rol meteran, palu, penggaris besi siku, engsel, cat kuas, sekrup, cat avian, kunci pas, thinner secial b) Bahan : 1) Ukuran kayu untuk kaki depan $83 \mathrm{~cm}$. 2) Ukuran kayu untuk kaki belakang 72,5 cm. 3) Ukuran kayu untuk bagian horizontal atas $32 \mathrm{~cm}$. 4) Ukuran kayu untuk bagian horizontal bawah $58 \mathrm{~cm}$. (2) Langkah kedua siswa tunarungu diberikan materi tentang praktek membuat dua kaki depan misalnya : a) Mengukur kayu dengan ukuran panjang $83 \mathrm{~cm}$. b) Memotong kayu dengan gergaji dengan ukuran 83 X 3 $\mathrm{X} 2 \mathrm{~cm}$. c) Bor lubang sebesar $10 \mathrm{~mm}$ di (3/8) bagian muka $11 \mathrm{~cm}$ dari bagian ujung atas. d) Bor dua lubang sebesar $10 \mathrm{~mm}$ di bagian muka 22,5 c, dari ujung bawah. (3) Langkah ketiga siswa tunrungu diberikan materi tentang praktek membuat satu kaki belakang misalnya : a) Mengukur kayu dengan panjang $83 \mathrm{~cm}, 72,5 \mathrm{~cm}, 32 \mathrm{~cm} 58 \mathrm{~cm}$. b.) Memotong kayu dengan gergaji dengan ukuran $83 \mathrm{~cm}, 72,5 \mathrm{~cm}, 32 \mathrm{~cm}$ $58 \mathrm{~cm}$. c.) Letakan dua kaki depan di lantai dengan satu kaki belakang di posis tengah. d) Sejajarkan lubang di bagian atas, pasang kayu horizontal atas ukur 32 X 3 x2 cm. e) Pasang kayu horizontal bawah ukuran 58 X 3 X 2 $\mathrm{cm}$. f) Pasang Baut-mur di lubanglubang yang sudah di bor. g) Pasang engsel di bagian tengah kayu horizontal atas. (4) Langkah keempat siswa tunarungu diberikan materi tentang praktek Finishing Cat misalnya :

a) Masukkan cat ke gelas plastik.

b) Tambahkan thinner ke gelas platsik. 
c) Aduk hingga tercampur.

d) Gunakan kuas untuk mengecat.

e) Cat warna kuning, merah, biru.

b. Post test dilakukan sama dengan pre test, untuk mengetahui pengaruh keterampilan easel untuk kemampuan vokasional siswa tunarungu.

Tabel 4.

hasil data post test Nilai kemampuan vokasional siswa tunarungu

\begin{tabular}{|c|c|c|c|}
\hline No & $\begin{array}{c}\text { Nama } \\
\text { siswa }\end{array}$ & $\begin{array}{c}\text { Jenis } \\
\text { kelamin }\end{array}$ & $\begin{array}{c}\text { Nilai } \\
\text { kemampuan } \\
\text { hasil belajar } \\
\text { post test }\end{array}$ \\
\hline 1 & $\mathrm{~F}$ & $\begin{array}{c}\text { Laki- } \\
\text { laki }\end{array}$ & 60 \\
\hline 2 & $\mathrm{Ri}$ & $\begin{array}{c}\text { Laki- } \\
\text { laki }\end{array}$ & 70 \\
\hline 3 & Ra & $\begin{array}{c}\text { Laki- } \\
\text { laki }\end{array}$ & 80 \\
\hline 4 & $\mathrm{D}$ & $\begin{array}{c}\text { Laki- } \\
\text { laki }\end{array}$ & 90 \\
\hline & \multicolumn{2}{|c|}{ Rata-rata } & $\mathbf{7 5}$ \\
\hline \multicolumn{4}{|c}{ (data diolah tahun 2020) } \\
\hline
\end{tabular}

Tabel 4

hasil data pre test dan post test untuk nilai kemampuan vokasional siswa tunarungu

\begin{tabular}{|c|c|c|c|}
\hline No & $\begin{array}{c}\text { Nama } \\
\text { siswa }\end{array}$ & Pre test & $\begin{array}{c}\text { Post } \\
\text { test }\end{array}$ \\
\hline 1 & $\mathrm{~F}$ & 50 & 60 \\
\hline 2 & $\mathrm{Ri}$ & 50 & 70 \\
\hline 3 & $\mathrm{Ra}$ & 30 & 80 \\
\hline 4 & $\mathrm{D}$ & 30 & 90 \\
\hline \multicolumn{2}{|c|}{ Rata-rata } & $\mathbf{7 5}$ \\
\hline
\end{tabular}

(data diolah tahun 2020)
Tabel 5.

Tabel probalilitas tanda hasil pre test dan hasil post test pemahaman Untuk nilai kemampuan vokasional siswa tunarungu

\begin{tabular}{|c|c|c|c|c|}
\hline No & $\begin{array}{c}\text { Nama } \\
\text { siswa }\end{array}$ & $\begin{array}{c}\text { Pre } \\
\text { test }\end{array}$ & $\begin{array}{c}\text { Post } \\
\text { test }\end{array}$ & $\begin{array}{c}\text { Perubahan } \\
\text { (+/-) }\end{array}$ \\
\hline 1 & $\mathrm{~F}$ & 50 & 60 & + \\
\hline 2 & $\mathrm{Ri}$ & 50 & 70 & + \\
\hline 3 & $\mathrm{Ra}$ & 30 & 80 & + \\
\hline 4 & $\mathrm{D}$ & 30 & 90 & + \\
\hline \multicolumn{2}{|c|}{ Rata-rata } & $\mathbf{4 0}$ & $\mathbf{7 5}$ & $\sum \mathbf{4}$ \\
\hline
\end{tabular}

(data diolah tahun 2020)

Pada hari Pertama siswa bernama $\mathrm{F}$, ketika melakukan pretest memperoleh nilai 50 dan saat melakukan posttest memperoleh nilai 60. Pengaruh treatment yang diperoleh F kurang meningkat, di karenakan saat melakukan treatment $\mathrm{F}$ kurang fokus terhadap treatment yang diberikan, $\mathrm{F}$ lebih cenderung suka mengajak temanteman sekelasnya mengobrol. Ketika treatment diulang kembali siswa juga masih susah untuk fokus terhadap treatment yang diberikan. Saat melakukan F treatment kurang fokus , suka toleh-toleh dan berbicara terus sehingga materi yang di berikan lupa.

Kedua siswa bernama $\mathrm{Ri}$, ketika melakukan pre test memperoleh nilai 50 dan saat melakukan pos test memperoleh nilai 70 . $\mathrm{Ri}$ terlihat meperhatikan dan menyimak materi keterampilan easel yang diberkah. Siswa Ri pada saat pre test memperoleh nilai 50, sehingga penelitian memberikan treatment berupa keterampilan easel. Pada saat treatment - Pada saat Mengerjakan pretest dan postest juga membutuhkan waktu yang 
sedikit lebih lama. Nilai yang diperoleh Ri saat post test adalah 50 dan pada saat post test 70 .

Ketiga siswa bernama Ra, ketika melakukan pretest memperoleh nilai 30 dan saat melakukan postest memperoleh nilai 80. Pengaruh treatment yang diberikan kepada $\mathrm{Ra}$ cukuplah besar, yang mulanya Ra tidak memahami tentang materi pemahaman Keterampilan Easel menjadi memahami. Saat melakukan treatment $\mathrm{Ra}$ sangat memperhatian meskipun teman-temannya menggangu namun $\mathrm{Ra}$ tetap fokus memeperhatian kemampuan vokasional.

Keempat siswa bernama D, ketika melakukan pre test memperoleh nilai 30 dan saat melakukan postest memperoleh nilai 90. Hal yang diperoleh D sangatlah tinggi, dikarenakan sat melakukan treatment $\mathrm{K}$ dapat menyimak dan memperhatikan selain itu d mampu menceritakan isi easel tersebut kepada teman-temannya dikelas, sehingga $\mathrm{D}$ tidak memperlukan pengulangan treatment.

Pada saat pre test $\mathrm{F}$ dan $\mathrm{Ri}$ mendapatkan nilai 50 karena kurang fokus dan tergesa-gesa, sedangkan $\mathrm{Ra}$ dan D mendapatkan nilai 30 karena kurang memahami pada saat praktik membuat easel. Pada saat post test dengan menggunakan media easel $\mathrm{F}$ mulai memahami pada saat praktik membuat easel yang diberikan sehingga mendapat nilai $60, \mathrm{Ri}$ mendapat nilai 70 dalam hal ini mulai fokus dan pada saat praktik membuatan easel, Ra mampu mempraktikkan membuatan easel yang diberikan dengan baik dan tidak ada kendala dengan nilai yang didapatkan 80 sedangkan D mendapat nilai 90 dianggap sangat mampu mempraktikan pembuatan easel.

Saat treatment berlangsung ada sedikit kendala, di antarnya kelas siswa yang harus dibagi menjadi 3 kelas dalam satu ruang sehingga siswa lain banyak yang mondar-mandir dan ada yang penasaran dengan keterampilan easel. Jadi siswa lain pun diperolehkan untuk menyimak keterampilan easel meskipun tidak mengikuti treatment, asal tidak mengganggu kegiatan pembuatan easel yang sedang berlangsung.

\section{PENUTUP}

\section{Simpulan}

Dari hasil penelitian maka dapat disimpulkan bahwa ada pengaruh keterampilan easel terhadap kemampuan vokasional siswa tunarungu kelas IV SDLB-B di SLB-B dan Autis TPA Jember Tahun Ajaran 2019/2020. Terbukti dari hasil nilai rata-rata pada saat pre test 40 dan ratarata dari post test 75 serta hasil dari nilai statistik diperoleh $Z_{H}=2>1,645$ maka dapat disimpulkan Ho (hipotesis nol ) ditolak dan Ha (hipotesis kerja) diterima. Pada pelaksanan kegiatan penelitian ini terbukti bahwa bahwa keterampilan easel dapat menarik minat siswa dalam mengikuti proses pembelajran yang diberikan. 
Saran

Ada berberapa saran sebagai berikut :

1. Bagi peneliti berguna untuk dijadikan awan untuk melaksanakan penelitian lebih mengenai keterampilan easel unuk siswa tunarungu.

2. Bagi guru hasil penelitian ini bisa dibergunakan guru sebagai untuk melatih keterampilan vokasional untuk siswa tunarungu.

3. Bagi orang tua hasil penelitian ini bisa di pergunakan orang tua untuk melatihkan keterampilan vokasional dirumah agar anak memiliki keterampilan hidup di kemudian hari.

4. Untuk siswa hasil praktik dari penelitian ini dapat digunakan siswa tunarungu untuk membuka lapangan kerja setelah siswa tunarungu lulus dari sekolah agar tidak lagi bergantung pada orang tua.

\section{DAFTAR PUSTAKA}

Winarsih. (2007). Departemen Pendidikan dan Kebudayaan.

Arikunto, Suharsimi . (2016). Dasardasar Evealuasi Pendidikan. Jakarta : Bumi Aksara.

Sugiyono.(2017). Metode Penenlitian Kuantitatif, Kualitatif dan $R \& D$. Bandung : Alfabeta.

Hatta. (2009) Uji Z STATISTA. Dari wordpers. (http://2sat.wordpers.com, diakses 28 Juli 2018. 